\title{
Photoreactions between [60]Fullerene and Various Aromatic Tertiary Amines
}

\author{
Yosuke Nakamura,* Masato Suzuki, Kyoji O-kawa, Takashi Konno, and Jun Nishimura* \\ Department of Nano-Material Systems, Graduate School of Engineering, Gunma University, \\ Tenjin-cho, Kiryu, Gunma 376-8515, Japan
}

\section{Supporting Information}

1) General experimental methods $\quad \mathrm{S} 2$

2) ${ }^{1} \mathrm{H}$ NMR spectrum of $\mathbf{2 a}$ in $\mathrm{CDCl}_{3}$. S3

3) ${ }^{1} \mathrm{H}$ NMR spectrum of $\mathbf{3 a}$ in $\mathrm{CDCl}_{3}$.

4) ${ }^{1} \mathrm{H}$ NMR spectrum of $\mathbf{4 a}$ in $\mathrm{CDCl}_{3}$. S5

5) ${ }^{1} \mathrm{H}$ NMR spectrum of $\mathbf{3 b}$ in $\mathrm{CDCl}_{3}$. S6

6) ${ }^{1} \mathrm{H}$ NMR spectrum of $\mathbf{4 b}$ in $\mathrm{CDCl}_{3}$.

7) ${ }^{1} \mathrm{H}$ NMR spectrum of $\mathbf{2 d}$ in $\mathrm{CDCl}_{3}$.

8) ${ }^{1} \mathrm{H}$ NMR spectrum of $\mathbf{3 d}$ in $\mathrm{CDCl}_{3}$.

9) UV-Vis spectrum of $\mathbf{2 a}$ in cyclohexane $\quad \mathrm{S} 10$

10) UV-Vis spectrum of $\mathbf{3 a}$ in cyclohexane $\quad$ S11

11) UV-Vis spectrum of $\mathbf{4 a}$ in cyclohexane $\quad \mathrm{S} 12$

12) UV-Vis spectrum of $\mathbf{3} \mathbf{b}$ in benzene $\quad \mathrm{S} 13$

13) UV-Vis spectrum of $\mathbf{4 b}$ in benzene $\quad \mathrm{S} 14$

14) UV-Vis spectrum of $\mathbf{2} \mathbf{d}$ in cyclohexane $\quad$ S15

15) UV-Vis spectrum of $\mathbf{3 d}$ in cyclohexane $\quad$ S16 
1) General experimental methods

A mixture of $N, N$-dimethylaniline $1 \mathbf{a}(970 \mathrm{mg}, 8.0 \mathrm{mmol})$ and [60]fullerene (288 $\mathrm{mg}, 0.4 \mathrm{mmol})$ in toluene $(500 \mathrm{ml})$ was irradiated with a 400-W high-pressure mercury lamp in a Pyrex vessel at room temperature for $6 \mathrm{~h}$. The reaction mixture was chromatographed on silica gel (toluene/hexane 1:9) and GPC (solvent; $\mathrm{CHCl}_{3}$ ), to give unreacted [60]fullerene, monoadduct $\mathbf{2 a}-\mathbf{4 a}$, and regioisomeric mixture of bisadducts. 
2) ${ }^{1} \mathrm{H}$ NMR spectrum of $\mathbf{2 a}$ in $\mathrm{CDCl}_{3}$.

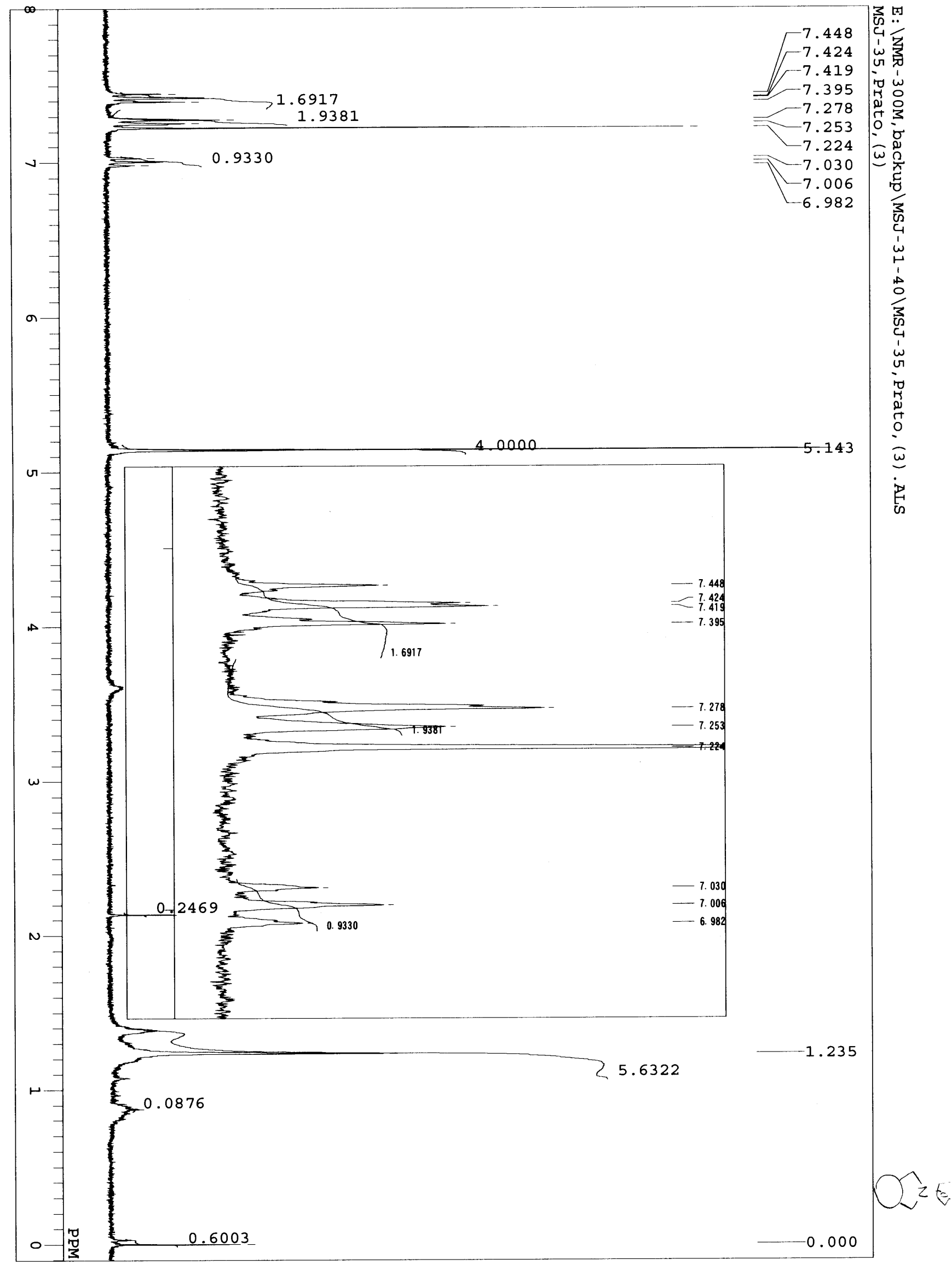

SB 
3) ${ }^{1} \mathrm{H}$ NMR spectrum of $\mathbf{3 a}$ in $\mathrm{CDCl}_{3}$.

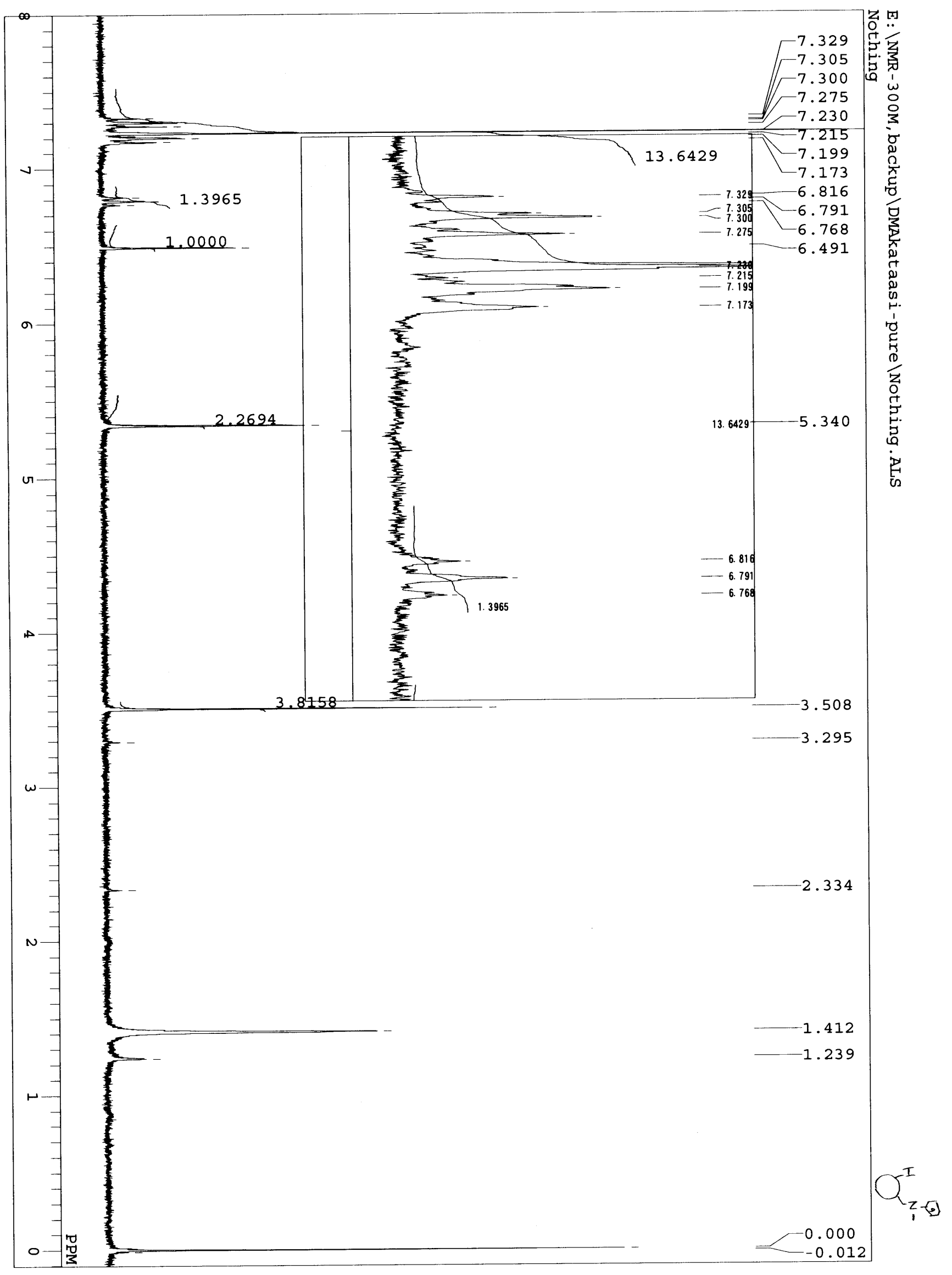


4) ${ }^{1} \mathrm{H}$ NMR spectrum of $\mathbf{4 a}$ in $\mathrm{CDCl}_{3}$.

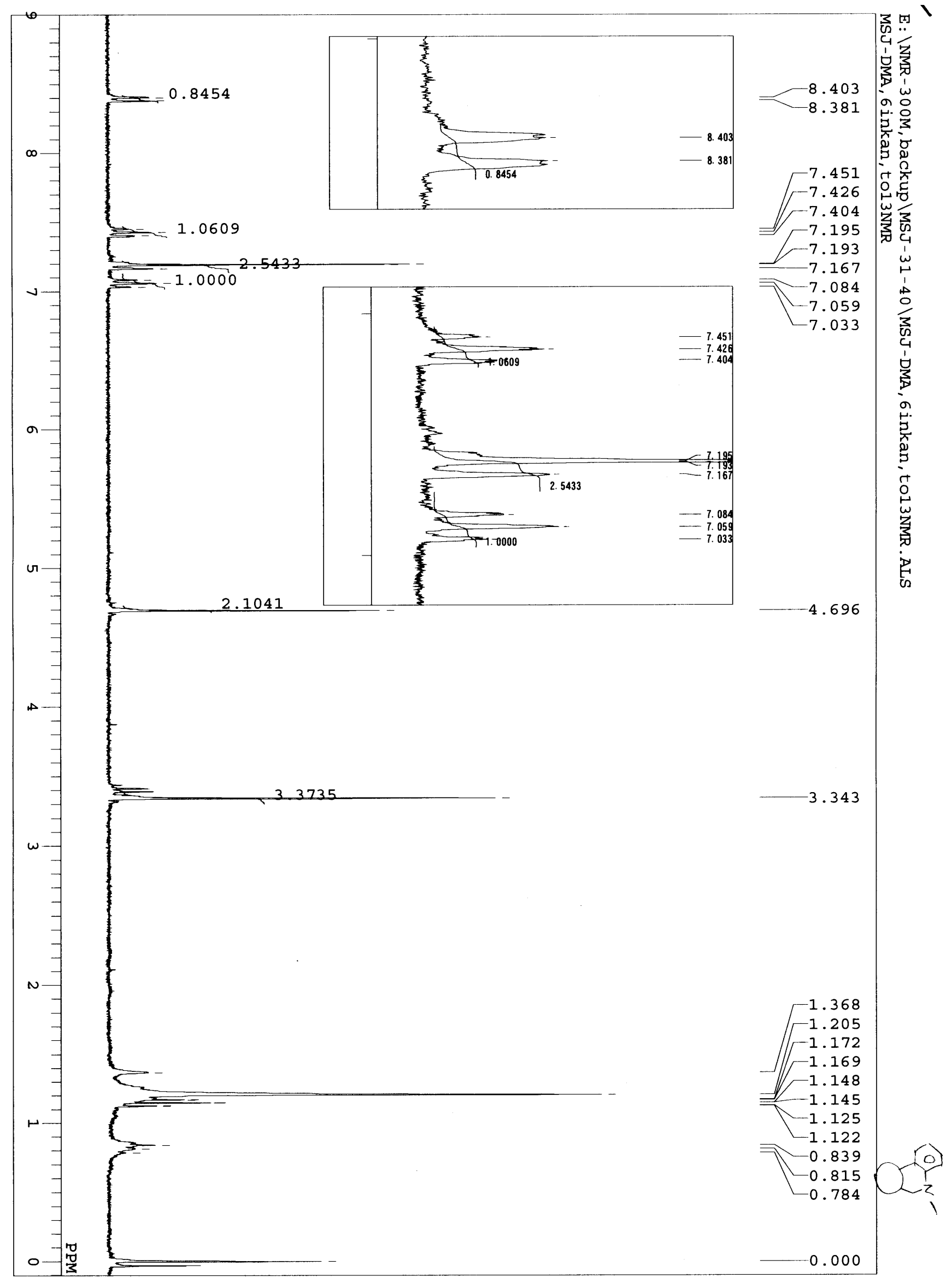


5) ${ }^{1} \mathrm{H}$ NMR spectrum of $\mathbf{3 b}$ in $\mathrm{CDCl}_{3}$.

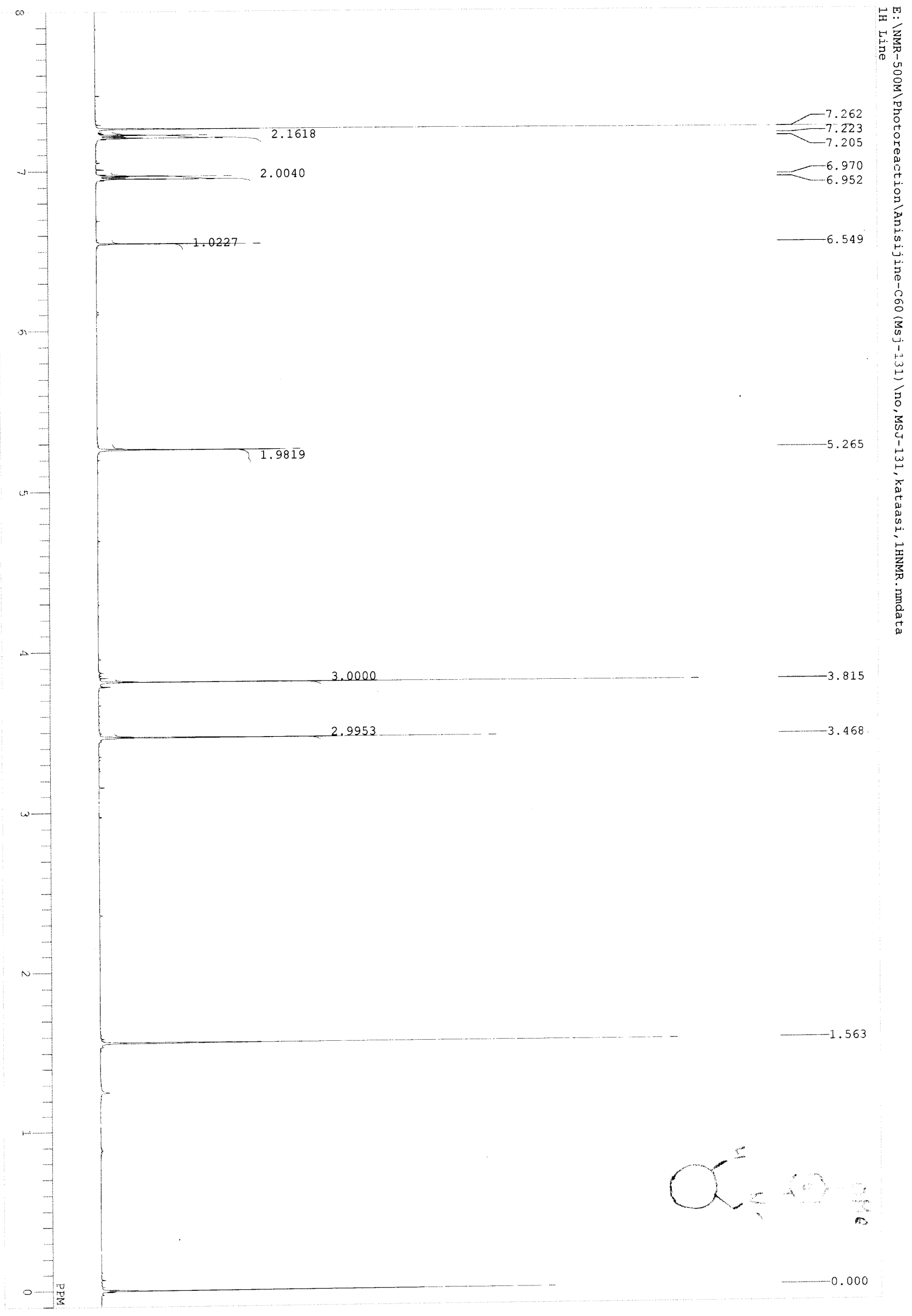


6) ${ }^{1} \mathrm{H}$ NMR spectrum of $\mathbf{4 b}$ in $\mathrm{CDCl}_{3}$.

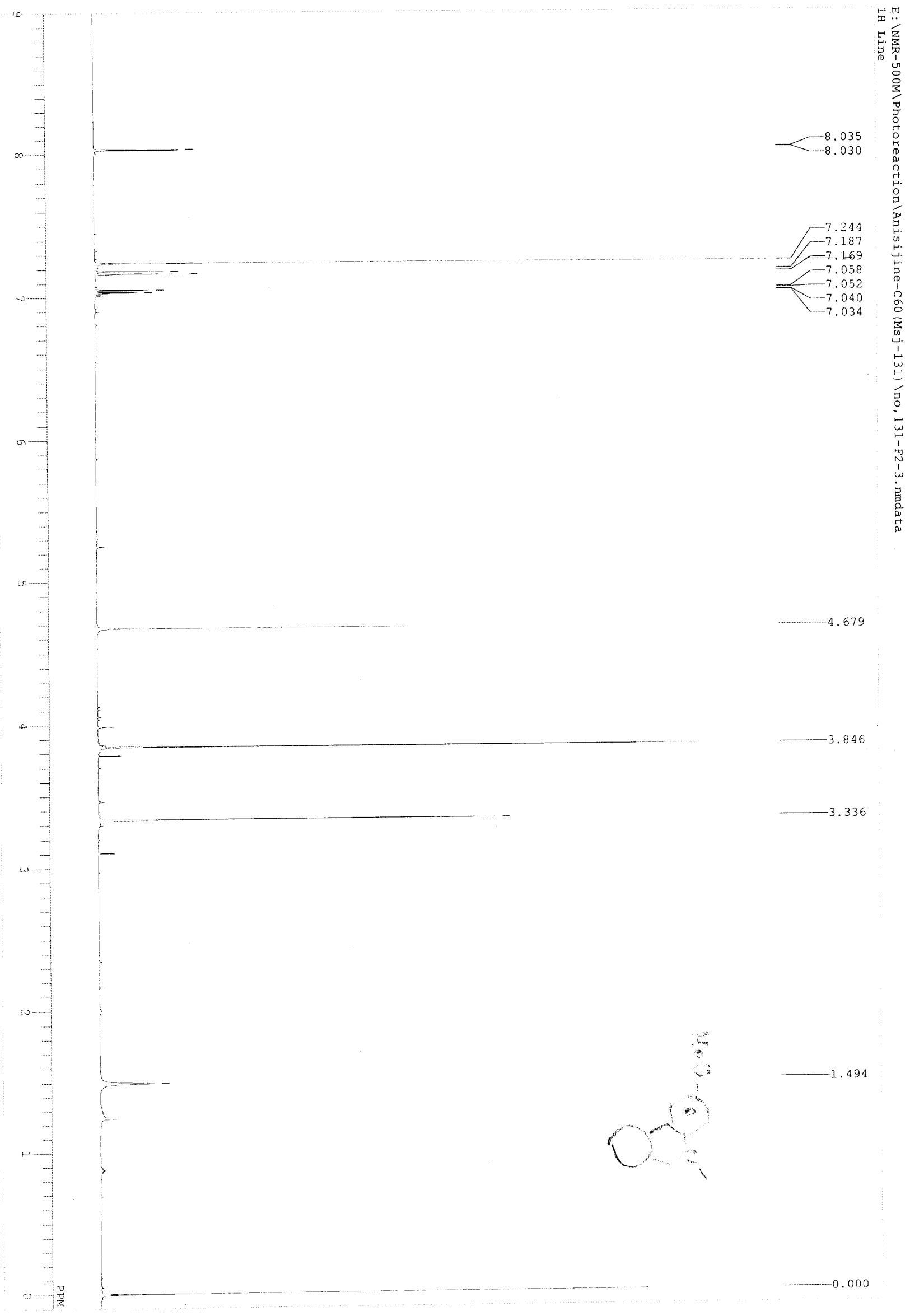


7) ${ }^{1} \mathrm{H}$ NMR spectrum of $\mathbf{2 d}$ in $\mathrm{CDCl}_{3}$.

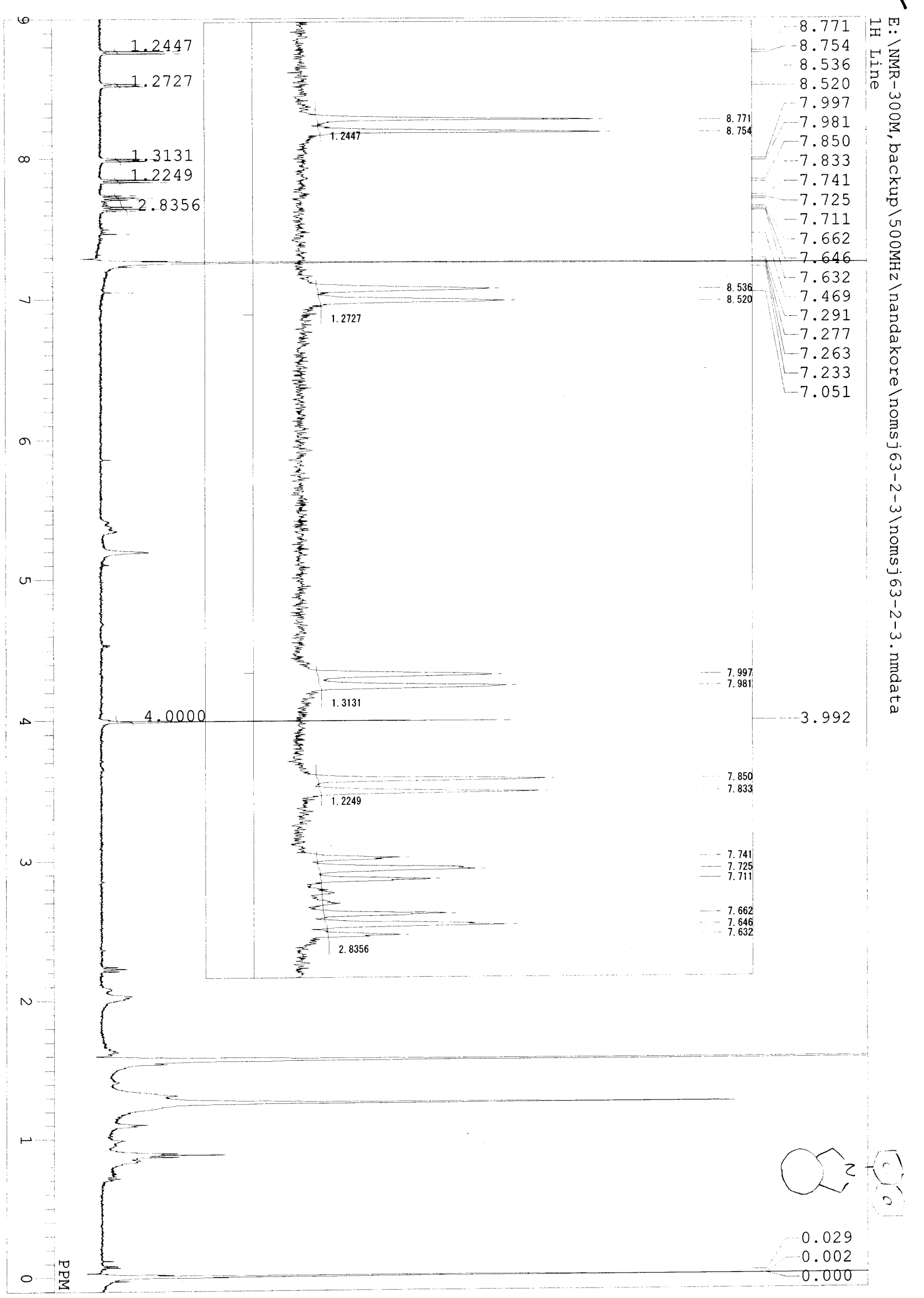


8) ${ }^{1} \mathrm{H}$ NMR spectrum of $\mathbf{3 d}$ in $\mathrm{CDCl}_{3}$.

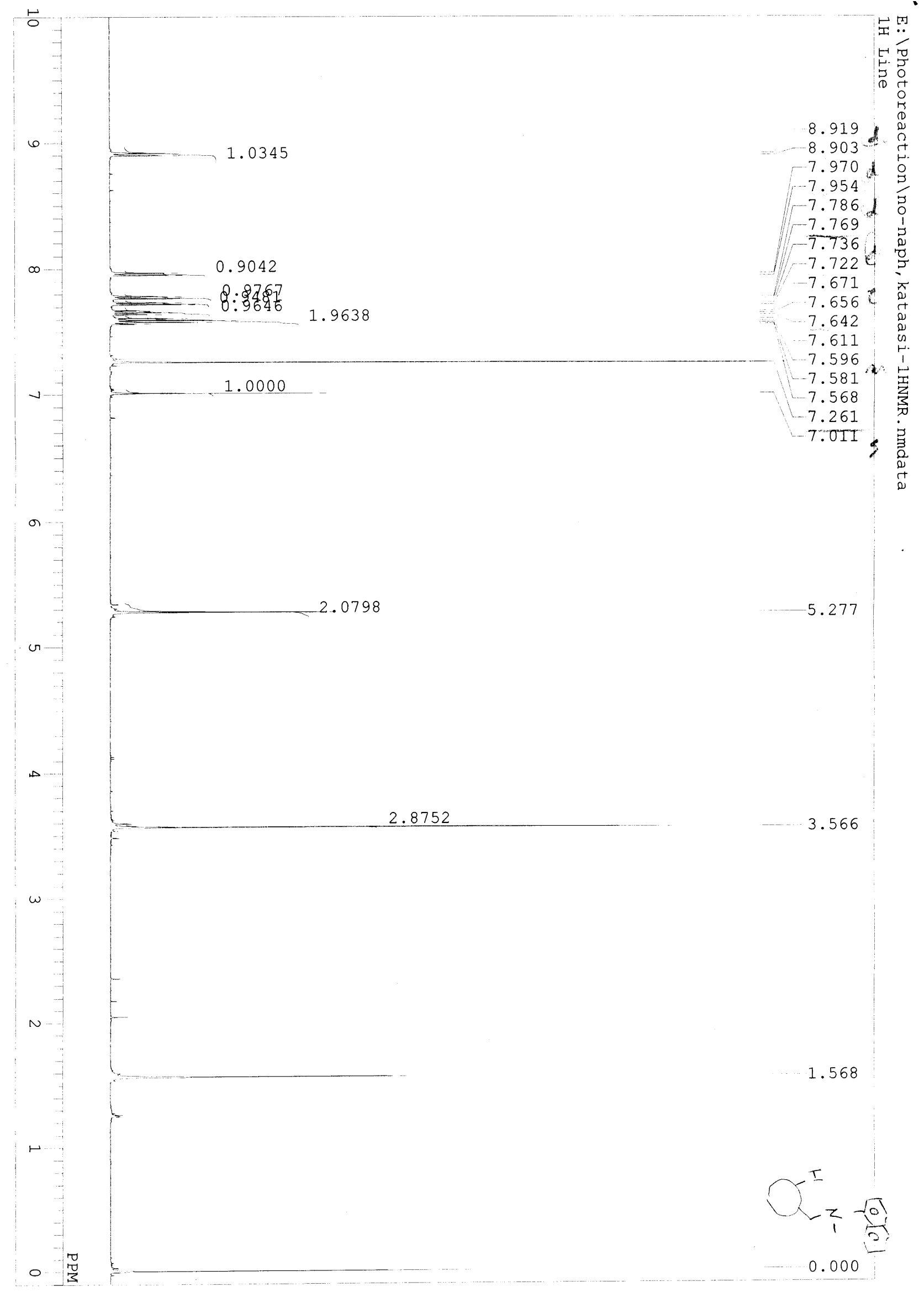


9) UV-Vis spectrum of $\mathbf{2 a}$ in cyclohexane

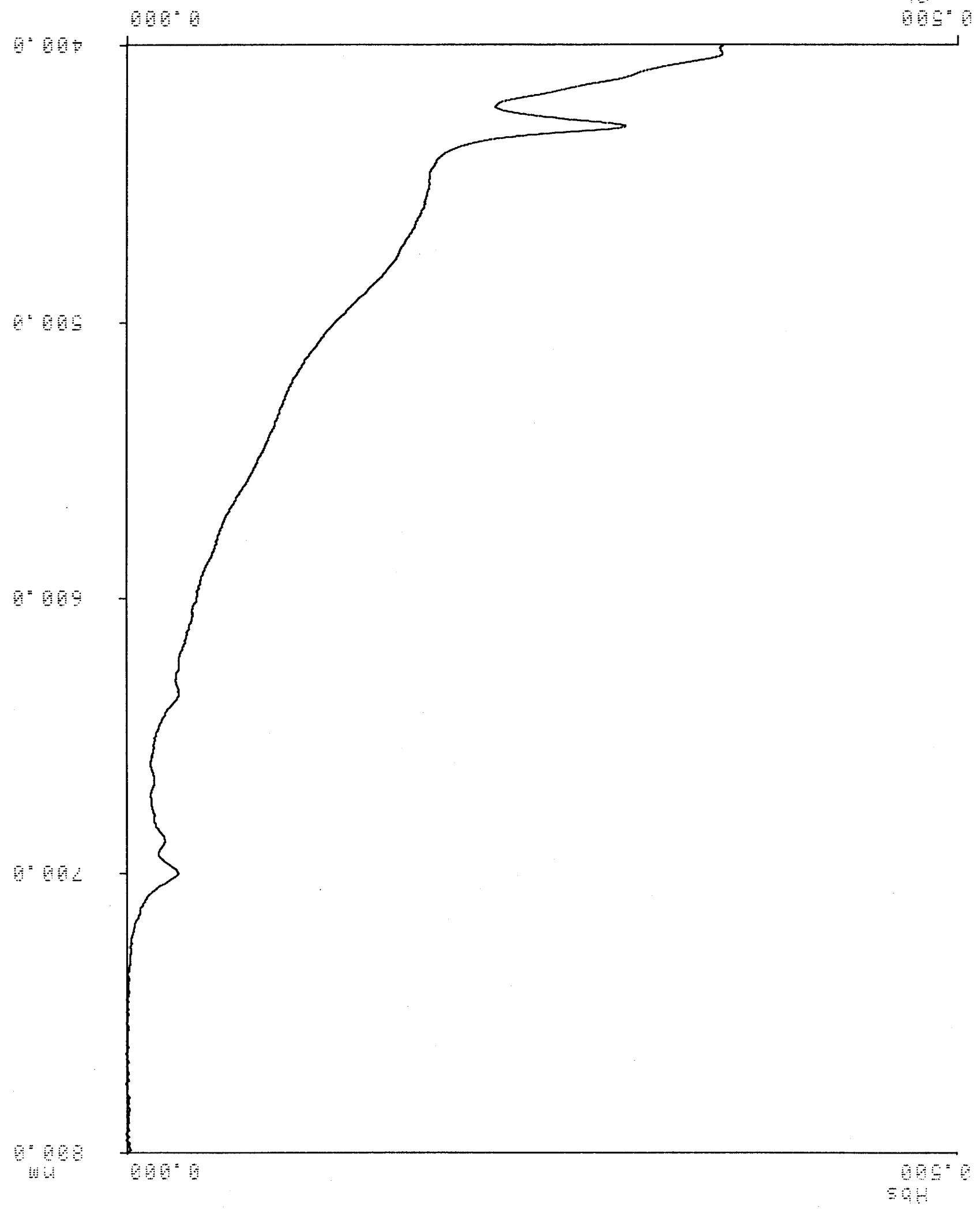


10) UV-Vis spectrum of $\mathbf{3 a}$ in cyclohexane

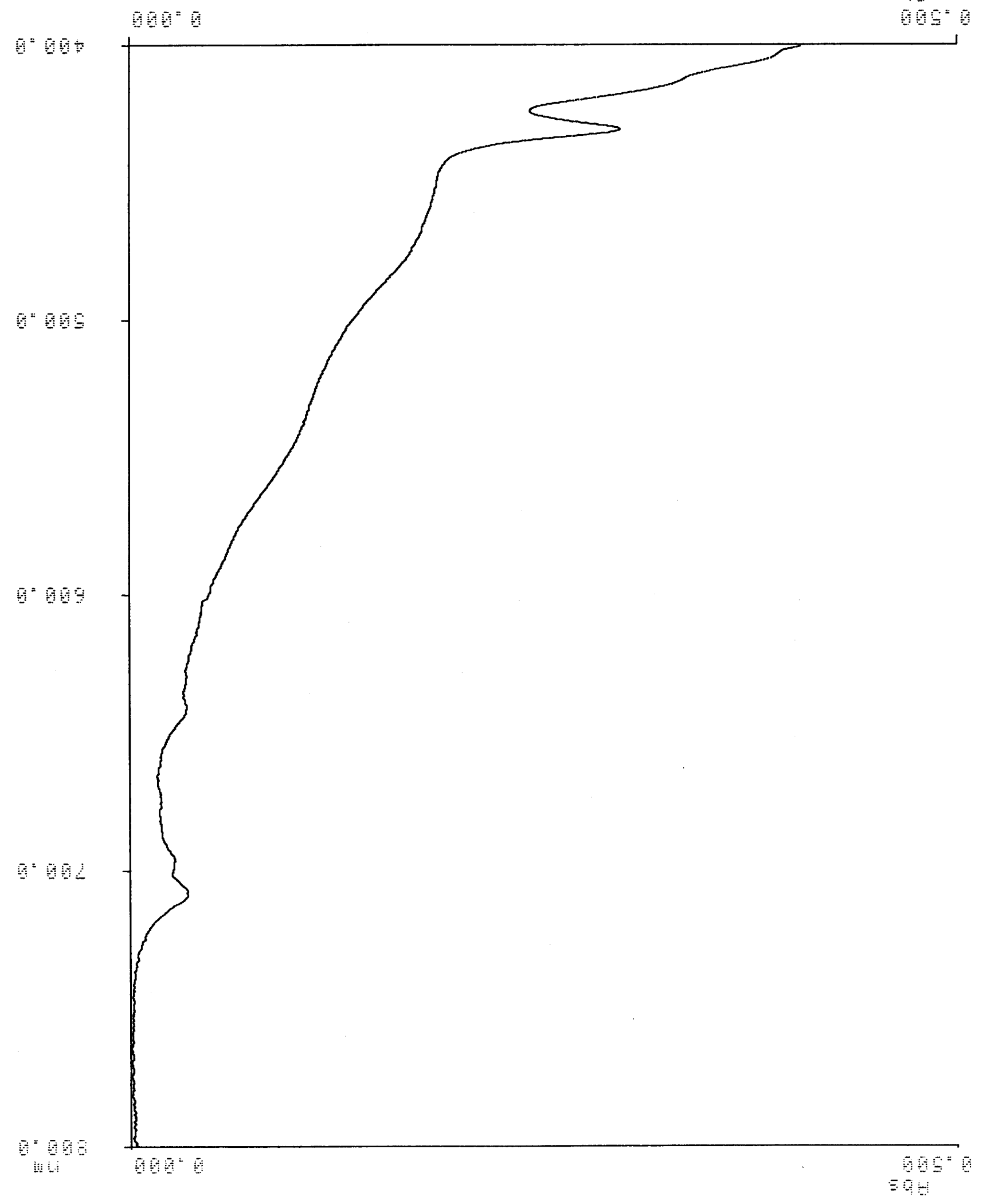


11) UV-Vis spectrum of $\mathbf{4 a}$ in cyclohexane

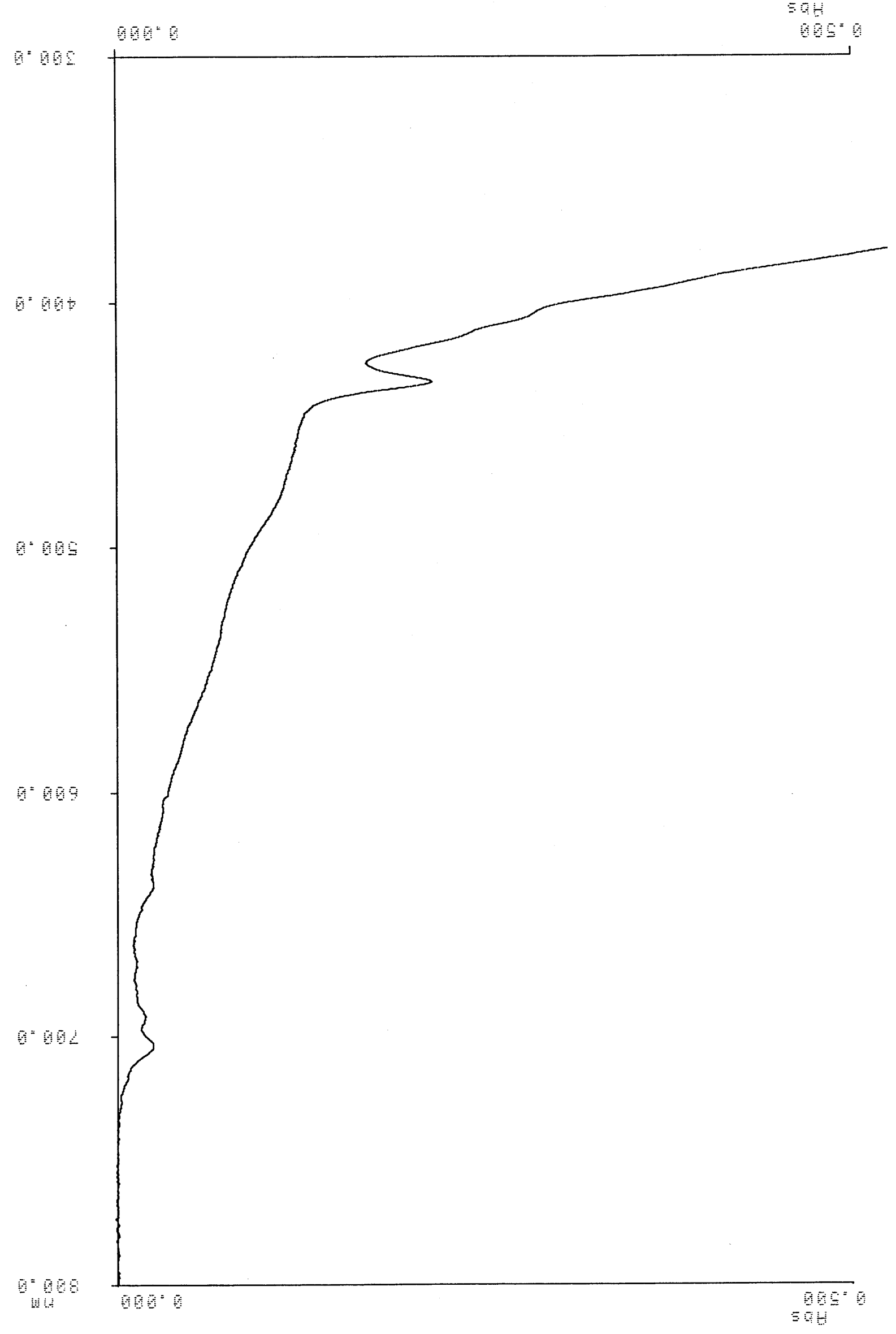


12) UV-Vis spectrum of $\mathbf{3} \mathbf{b}$ in benzene

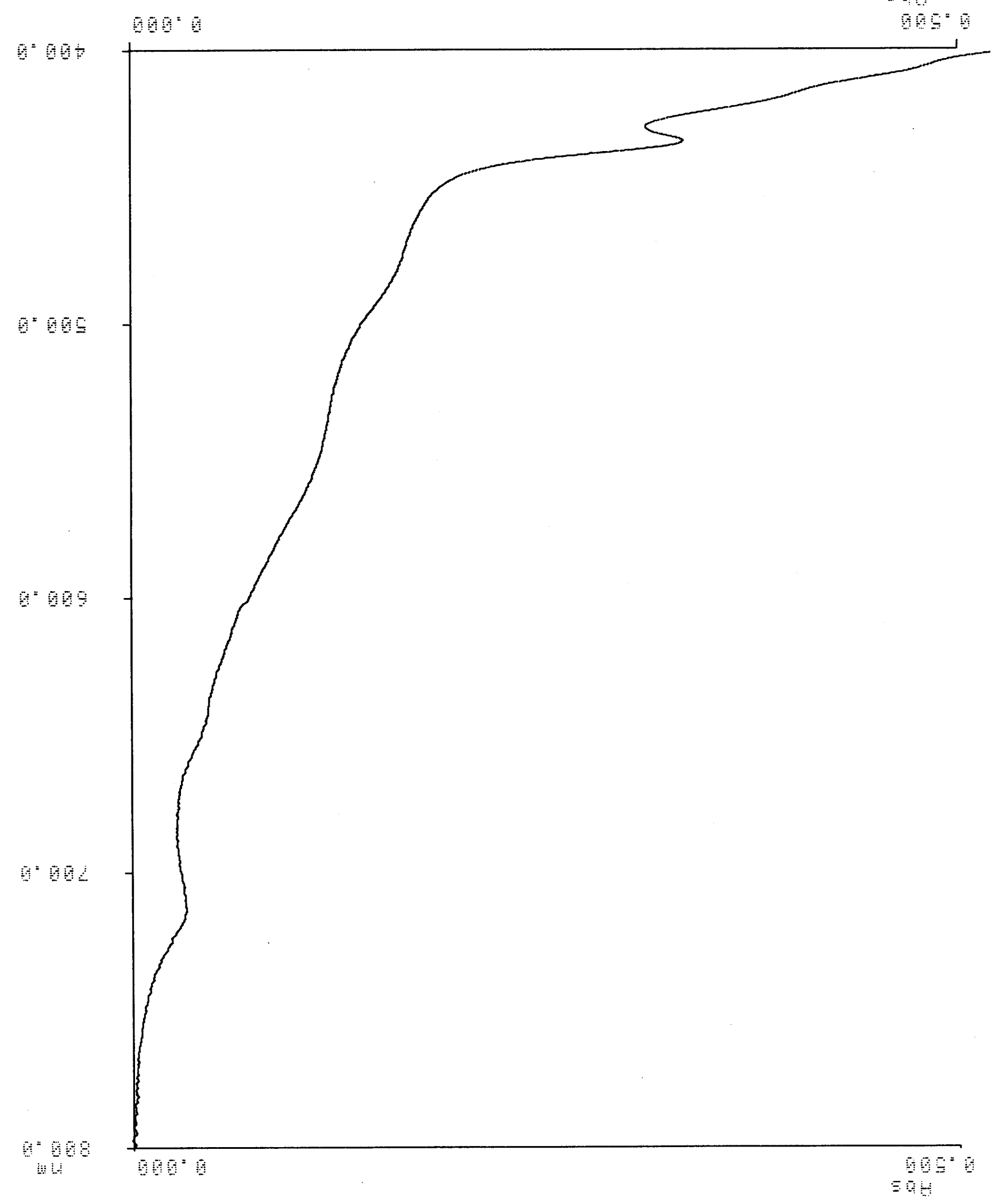


13) UV-Vis spectrum of $\mathbf{4 b}$ in benzene

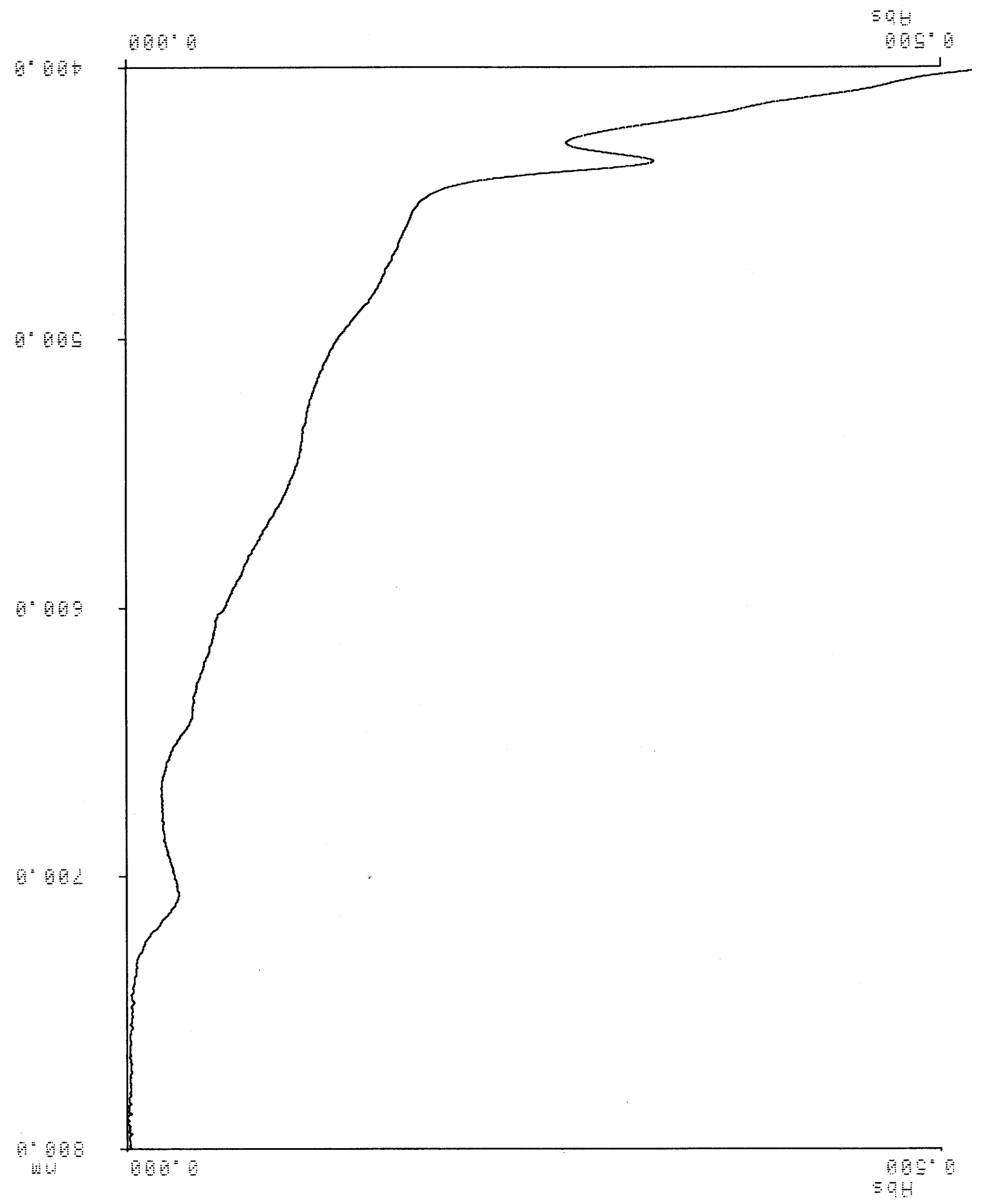


14) UV-Vis spectrum of $\mathbf{2} \mathbf{d}$ in cyclohexane

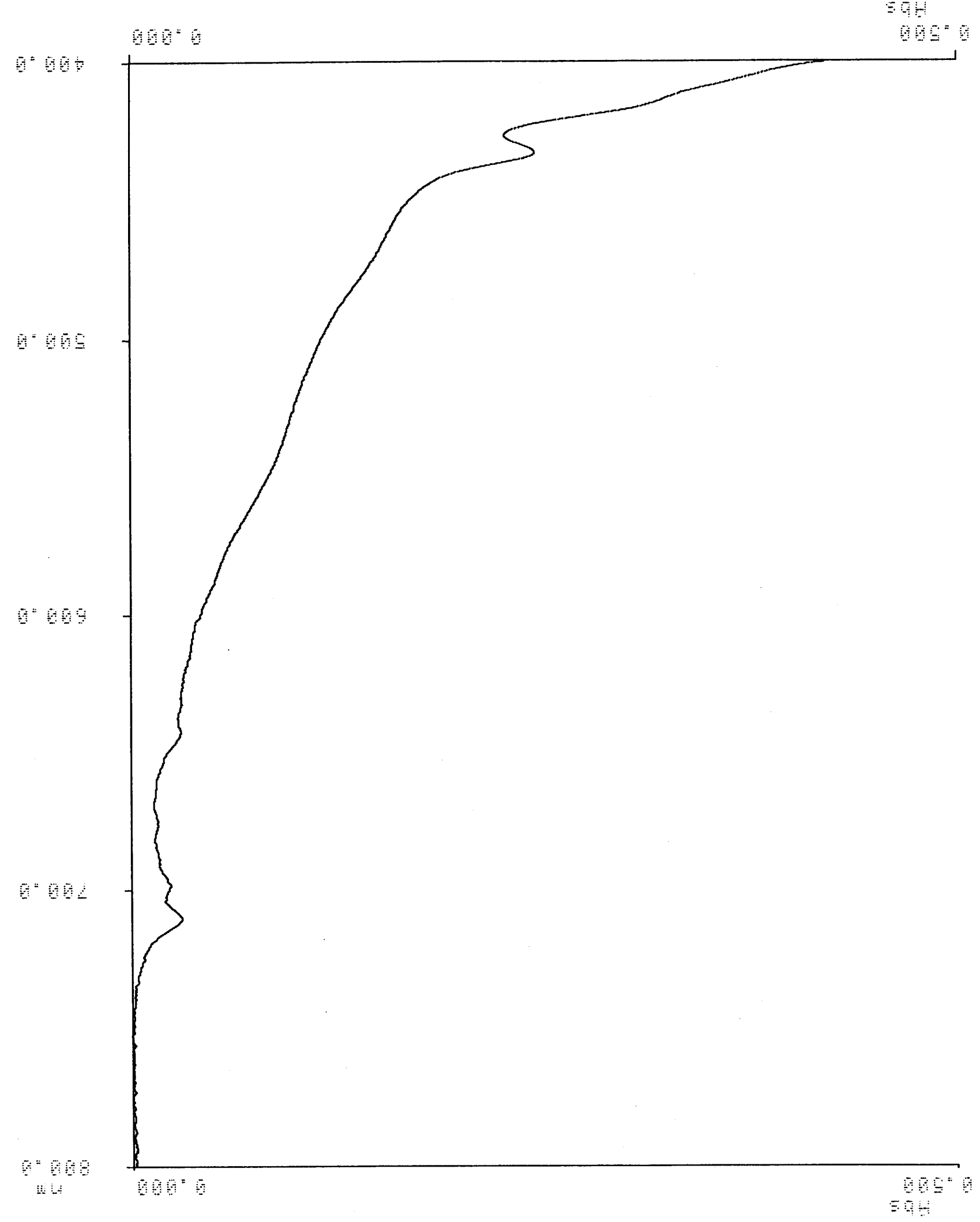


15) UV-Vis spectrum of $\mathbf{3 d}$ in cyclohexane

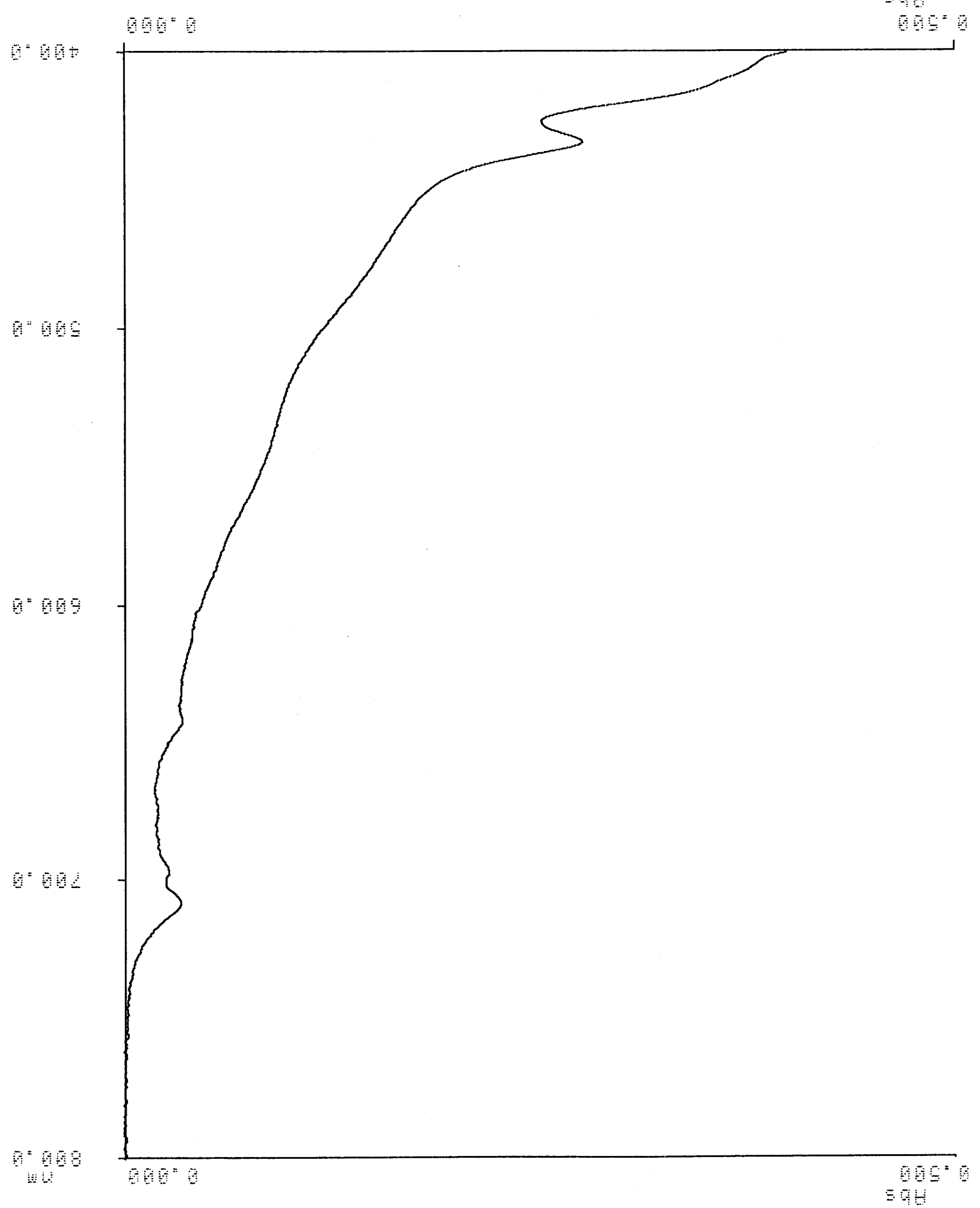

